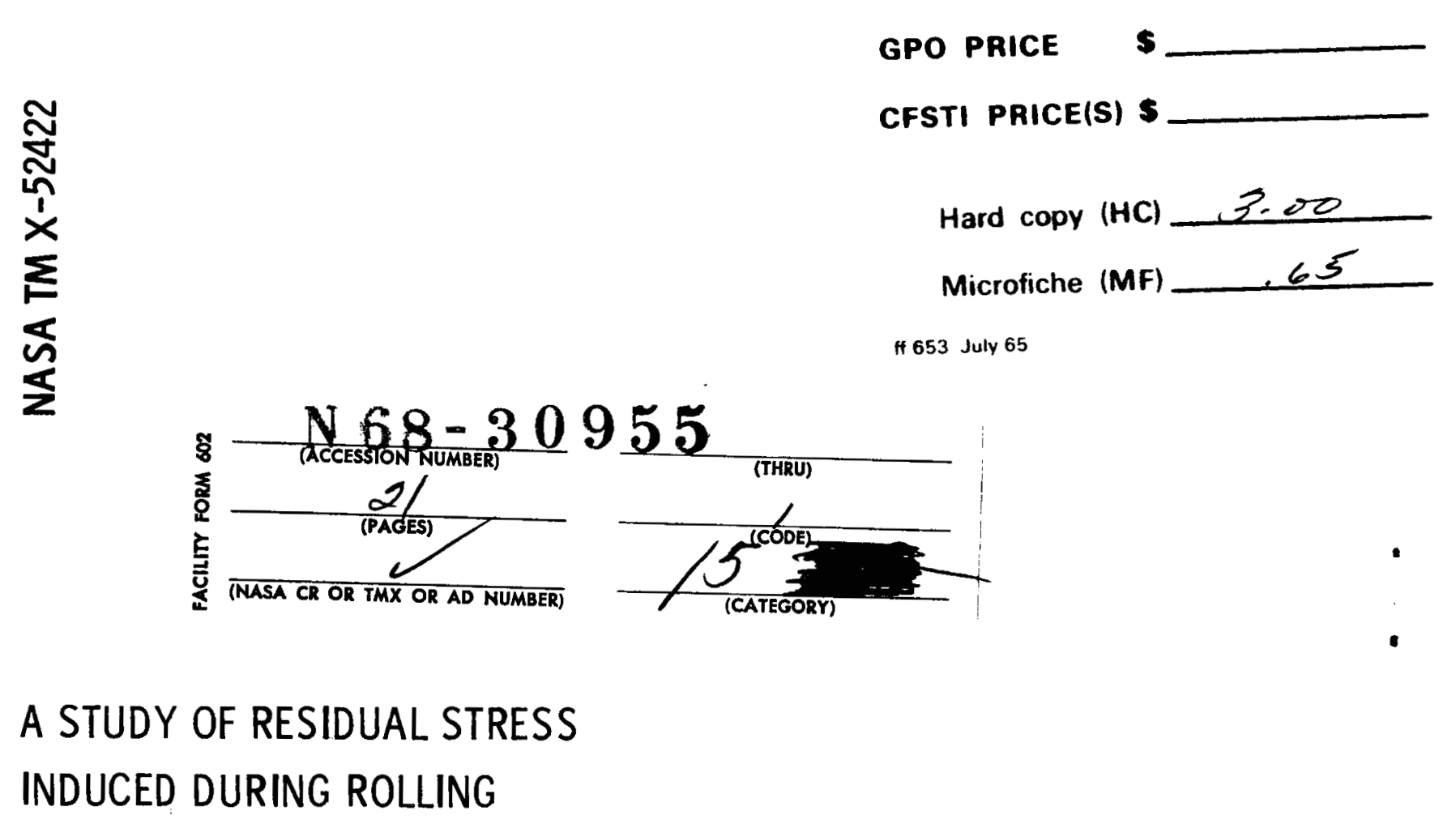

by E. V. Zaretsky, R. J. Parker, and W. J. Anderson

Lewis Research Center

Cleveland, Ohio

TECHNICAL PAPER proposed for presentation at Lubrication Conference sponsored by the American Society of Mechanical Engineers and the American Society of Lubrication Engineers Atlantic City, New Jersey, October 8-10, 1968

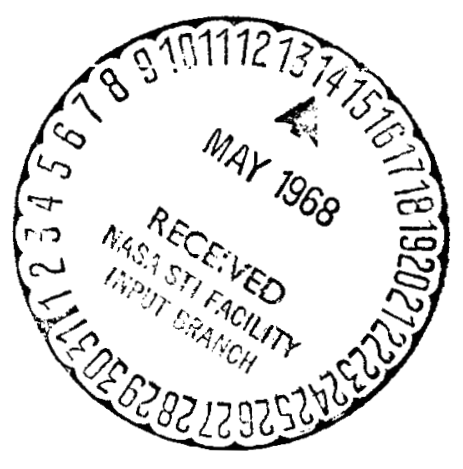

NATIONAL AERONAUTICS AND SPACE ADMINISTRATION - WASHINGTON, D.C. - 1968 
A STUDY OF RESIDUAL STRESS INDUCED DURING ROLLING

by E. V. Zaretsky, R. J. Parker, and W. J. Ander son

Lewis Research Center

Cleveland, Ohio

TECHNICAL PAPER proposed for presentation at

Lubrication Conference

sponsored by the American Society of Mechanical Engineers and the American Society of Lubrication Engineers Atlantic City, New Jersey, October 8-10, 1968 


\title{
A STUDY OF RESIDUAL STRESS INDUCED DURING ROLLING
}

\author{
by E. V. Zaretsky, ${ }^{*}$ R. J. Parker, and W. J. Anderson*
}

Lewis Research Center

National Aeronautics and Space Administration

Cleveland, Ohio

\begin{abstract}
Subsurface residual stress measurements were made on SAE 52100 steel inner races from 207 -size deep-groove ball bearings in which $\Delta H$ (ball hardness minus race hardness) ranged from -1.1 to 3.5 points Rockwell C. These bearings had been run at an inner-race speed of $2750 \mathrm{rpm}$ and a radial load of 1320 pounds producing maximum Hertz stresses of 352,000 and $336,000 \mathrm{psi}$ at the inner and outer races, respectively. The residual stress measurements were made in a circumferential direction at various depths below the inner-race running track surface for a total of 19 of these bearings that had been run for nominally 200,600 , and 1600 hours. The measurements indicated that the maximum compressive residual stresses occur in approximately the same $\Delta \mathrm{H}$ range for which the maximum fatigue lives were observed. Additionally, no relation between running time and residual stress could be determined from these measurements.

\section{INTRODUCTION}

Among the factors that can affect the fatigue life of a rolling element is subsurface residual stress $[1] .^{\dagger}$ Residual stresses can be produced in a material by such methods as heat treating, rolling, peening,

\footnotetext{
*Member ASME.
}

${ }^{\dagger}$ Numbers in brackets designate references at end of paper.
\end{abstract}


and severe grinding. These residual stresses can either increase or decrease the maximum shearing stress due to contact loading [2]。A compressive residual stress would reduce the magnitude of the maximum shearing stress and thus would increase fatigue life.

Almen [3] was the first to study residual stresses in rollingelement bearings in 1944. From these initial studies it was concluded that residual stresses increased in a rolling-element bearing with running time. Later results appear to have substantiated the findings of Almen [4] and [5]. The maximum value of these induced compressive residual stresses appears to occur at the depth of the maximum shearing stress [4] and [5]. Additional results [4] also indicated that the magnitude of the induced compressive residual stress was a function of the maximum Hertz stress. Further research showed that bearings, which had compressive residual stresses induced prior to operation exhibited lives exceeding those with no prior induced stress [6 and 7].

Research reported in [1] and [2] indicated that the compressive residual stresses induced in a bearing inner race during running is a function of the hardness of the rolling elements minus the race hardness, termed $\Delta H$. An interrelation was indicated between $\Delta H$, induced compressive residual stress, and fatigue life. The apparent maximum value of induced residual compressive stress occurred at a value where $\Delta \mathrm{H}$ was greater than zero.

In order to better understand the role of residual stresses in the rolling-contact phenomenon, it is necessary to measure these stresses as a function of depth below the surface for various bearing running times and material hardness combinations. Therefore, the objectives 
of the research described in this paper, which is based on the work reported initially in [8], were to investigate with full-scale bearings the relationship between residual stress as a function of depth below the rolling-element surface and component hardness; to determine the correlation between $\Delta H$, residual stress, and fatigue life; and to substantiate the relationship between induced compressive residual stress and running time. All experimental results were obtained with the same heat of material and lubricant batch.

\section{SPECIMENS AND PROCEDURE}

Fatigue tests were conducted with 207 -size deep-groove ball bearings [ 9 and 10]. The specifications of the bearings are as follows: Inner-race track dia, in. . . . . . . . . . . . 1.6648 Outer-race track dia, in. . . . . . . . . . 2. 5411 Ball dia, in. ...................... 0.4375 Inner race conformity, $\mathrm{f}_{\mathrm{i}}$, percent . . . . . . . . . 51 Outer race conformity, $\mathrm{f}_{\mathrm{o}}$, percent . . . . . . . . . . 52 Number of balls . . . . . . . . . . . . . . . 9

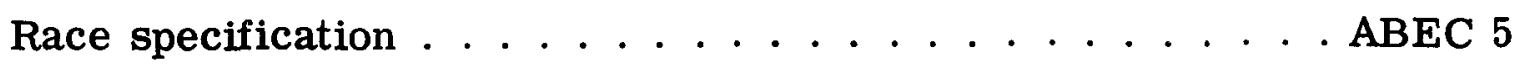

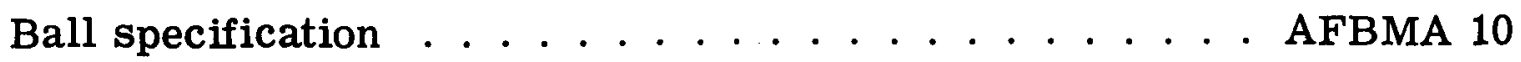
The inner and outer races of the bearings were from one heat of airmelted SAE 52100 steel formed from tubing and heat treated as follows:

1. The races were austenitized at $1500 \mathrm{deg} F$ for 20 minutes, 1530 $\operatorname{deg} \mathrm{F}$ for 20 minutes, and $1540 \mathrm{deg} \mathrm{F}$ for 20 minutes, and then oil quenched.

2. The inner races were tempered at $320 \mathrm{deg} F$ for 1 hour, air cooled and then given a second temper at $330 \mathrm{deg} F$ for 30 minutes. 
3. The outer races were tempered at $320 \mathrm{deg} F$ for 1 hour, air cooled, and then given a second temper at $320 \mathrm{deg} F$ for 30 minutes.

4. The final nominal hardness of the inner and outer races was Rockwell C 63.

All the balls for the bearings were made from one heat of air melted SAE 52100 steel and heat treated as follows: the balls were preheated at $1250 \mathrm{deg} F$ for 30 minutes, austenitized at $1530 \mathrm{deg} F$ for 30 minutes, and then oil quenched. The as-quenched hardness of the balls was approximately 66.5 Rockwell $\mathrm{C}$. The balls were then tempered according to the schedule shown in Table 1. The cleanliness ratings of the bearing material are given in Table 2 .

Four lots of bearings were assembled, each containing balls of a different hardness. These bearings were run at a radial load of 1320 pounds (producing maximum Hertz stresses of 352,000 and 336,000 psi at the inner and outer races, respectively), and a speed of $2750 \mathrm{rpm}$, with a super-refined naphthenic mineral oil lubricant and no heat added. The minimum elastohydrodynamic (EHD) film thickness under these conditions was approximately 24 microinches.

The results from these tests established the relationship between bearing fatigue life and $\Delta \mathrm{H}$ (ball hardness minus race hardness). Subsequent to test, each of the bearings was disassembled and the hardness on each component was measured. These actual component hardness measurements further substantiated the effect of $\Delta \mathrm{H}$ on fatigue life [9 and 10]. These bearings were then catagorized into running times. From these time catagories, three bearing inner-race groups were chosen: those which had been run for time intervals of 200 to 300 , 
600 to 700 , and 1600 to 1800 hours. The races from each time group had been run with actual $\Delta \mathrm{H}$ values ranging from -1 to 3.5 points Rockwell C. Subsurface residual stress measurements were made using standard X-ray diffraction techniques [11 and 12]. Each inner race was examined in the circumferential direction in the region directly beneath the running track. An electropolishing technique was used to remove material at varying depths (to $0.007 \mathrm{in}$.) below the surface.

\section{RESULTS AND DISCUSSION}

A typical residual stress pattern below the surface of an unrun bearing inner race is shown in Fig. 1. As can be seen, there exists a relatively high compressive residual stress very close to the surface which is a result of the fabricating process. This residual stress very rapidly diminishes just below the surface.

The residual stress pattern found beneath the surface of a rollingelement bearing inner race that has been run for 3480 hours is also shown in Fig. 1. The characteristic feature of this typical stress pattern is the high compressive stress at the surface. This stress decreases rapidly with depth, gradually levels out at some depth, and then decreases to zero.

The residual stress measurements on the 207-size deep-groove ball bearing inner races are summarized in Table 3 for varying values of $\Delta \mathrm{H}$. These residual stress data are also plotted in Fig. 2 as a function of depth below the surface for time intervals of 200 to 300,600 to 700 , and 1600 to 1800 hours.

For the time interval of 200 to 300 hours summarized in Fig. 2(a), no definitive relationship between $\Delta \mathrm{H}$ and residual stress is noted. 
The maximum value of subsurface compressive residual stress was approximately $51 \times 10^{3}$ psi at 0.003 inch below the surface for the $\Delta H$ of -1.3 points Rockwell C (Table 3 ).

For the time interval of 600 to 700 hours summarized in Fig. 2(b), a distinct relationship between $\Delta \mathbf{H}$ and residual stress is apparent. The maximum subsurface residual stress value occurs at a $\Delta H$ of 1.3 points Rockwell $\mathrm{C}$; the maximum value being $103 \times 10^{3}$ psi at a depth 0.002 inch below the surface (Table 3 ). The low residual stress values occur at the extreme $\Delta \mathrm{H}$ values. Higher residual stress values occur at the intermediate $\Delta \mathrm{H}$ values.

The time interval of 1600 to 1800 hours is summarized in Fig. 2(c). As for the time interval of 600 to 700 hours, a distinct relationship is noted between $\Delta \mathrm{H}$ and residual stress. Here again residual stress apparently increases to an intermediate value of $\Delta \mathrm{H}$ and then begins to decrease. The maximum residual stress values occur at a $\Delta H$ of 2.2 points Rockwell $C$. The maximum residual stress value at this $\Delta H$ is $78 \times 10^{3}$ psi at a depth of 0.002 inch below the surface (Table 3 ).

Fatigue results [9 and 10] for the bearing specimens reported herein indicated that fatigue lives increased with increasing $\Delta \mathrm{H}$ to a $\Delta \mathrm{H}$ value between 1 and 2 points Rockwell $\mathrm{C}$ and then decreased with further increase in $\Delta \mathrm{H}$. The maximum induced compressive residual stress occurred in the same range of $\Delta \mathrm{H}$ as did the maximum fatigue lives. These results substantiate an interrelation among $\Delta \mathrm{H}$, induced compressive residual stresses, and fatigue life.

In order to verify the phenomenon of increasing residual stress with running time, the residual stress data of Table 3 are plotted as 
a function of depth for various running times within a particular $\Delta \mathrm{H}$ range in Fig. 3. In general, no relation of induced residual stress and running time is apparent. It is speculated that, if residual stress is a function of time, the maximum residual stress values were reached before 200 hours of operation in the tests reported.

For the bearing inner races previously discussed, the peak amplitude of the maximum orthogonal shearing stress, $\tau_{z y}$, occurred at a depth of approximately 0.003 inch below the running track surface; whereas the peak amplitude of the maximum shearing stress, $\tau_{\max }$ occurred at a theoretical depth of approximately 0.006 inch. The maximum induced compressive residual stress occurs in these races at a depth of 0.002 to 0.003 inch below the running track surface which corresponds to the depth of the maximum orthogonal shearing stress. This correlation would suggest that the orthogonal shearing stress is the stress which is instrumental in inducing the residual stress. This is contrary to the conclusions of [5] and [6].

In [13] and [14] the maximum orthogonal shearing stress was assumed to be the critical stress instrumental in the rolling-element fatigue process. This assumption is reasonably valid if one considers that the maximum reversal of shearing stress occurs on the orthogonal plane. However, metallurgical investigation [15] of failed rollingelement specimens suggests that the maximum shearing stress, $\tau_{\text {max' }}$ which is on a $45^{\circ}$ plane, is the stress instrumental in producing fatigue cracks. This stress is greater in magnitude than the maximum orthogonal shearing stress, $\tau_{\mathrm{zy}}$. 
If a two-dimensional model is considered where it is assumed that the residual stress occurs only in the direction of rolling, an analysis indicates that this residual stress is added to the principal stress distribution caused by two bodies in contact [2]. A further analysis indicates a change in the maximum shearing stress but no change in the maximum orthogonal shearing stress. Because fatigue life is related to the magnitude of the residual stress present, it must be concluded that the shearing stress responsible for affecting rolling-element fatigue life is that which is more greatly affected by the residual stress. Therefore, the prime stress responsible for affecting life is the maximum shearing stress.

Residual stress can either increase or decrease the maximum shearing stress [2] according to the following equation:

$$
\left(\tau_{\max }\right)_{\mathrm{r}}=\tau_{\max }-\frac{1}{2}\left( \pm \mathrm{S}_{\mathrm{r}}\right)
$$

where $\left(\tau_{\max }\right)_{\mathbf{r}}$ is the maximum shearing stress modified by the residual stress, $\mathrm{S}_{\mathrm{r}}$, and $\tau_{\max }$ is the maximum shearing stress due to the applied load. The positive or negative sign indicates a tensile or compressive residual stress, respectively. A compressive residual stress would reduce the magnitude of the maximum shearing stress (because the value of $\tau_{\max }$ is negative) and increase fatigue life according to the inverse relationship between life and stress where

$$
\text { Life } \propto\left[\frac{1}{\left(\tau_{\max }\right)_{r}}\right]^{9}
$$


Using these equations the relative lives were calculated based on the residual stresses given in Table 3 at the depth of the maximum shearing stress, 0.006 inch below the running track surface for a running time of 600 to 700 hours. These results are compared with the relative experimental lives from [9] and [10] in Table 4. As can be seen, there is a qualitative correlation between the relative predicted lives and the relative lives determined experimentally. In both cases, the peak value occurs at a $\Delta \mathrm{H}$ between 1 and 2 points Rockwell C. At a depth of 0.006 inch for a running time of 1600 to 1800 hours, the peak life prediction would have been at a $\Delta \mathrm{H}$ between 2 and 3 points Rockwell $\mathrm{C}$. For the 200- to 300-hour running time, no life trend could have been predicted based on residual stress effects at the depth of the maximum shearing stress.

\section{SUMMARY}

Subsurface residual stress measurements were made on three groups of SAE 52100 steel inner races from 207-size deepgroove ball bearings which had been run for approximately 200,600, or 1600 hours. Operating conditions included an inner-race speed of 2750 rpm, a radial load of 1320 pounds, which produced maximum Hertz stresses of 352,000 and 336,000 psi at inner and outer races, respectively, and a super-refined naphthenic mineral oil as the lubricant. Each group of bearings had a range of $\Delta \mathrm{H}$ (ball hardness minus race hardness) from -1.1 to 3.5 points Rockwell C. The following results were obtained:

1. A qualitative correlation exists between relative predicted lives based upon measured residual stress and relative lives determined experimentally. 
2. A trend exists showing maximum values of induced subsurface compressive residual stresses at intermediate values of $\Delta H$. The peak value of residual stress apparently occurs in the same range of $\Delta \mathbf{H}$ for which maximum fatigue life occurs; thus substantiating the interrelation among induced compressive residual stress, rollingelement fatigue, and $\Delta \mathrm{H}$.

3. Maximum values of induced compressive residual stresses occurred at a depth between 0.002 and 0.003 inch which corresponds to the depth of the maximum orthogonal shearing stress, 0.003 inch below the running track surface.

4. No clear effect of running time on induced compressive residual stress was observed.

\section{ACKNOWLEDGEMENT}

The authors would like to acknowledge the invaluable help of the personnel from the General Motors Research Laboratories who performed the residual stress measurements.

\section{REFERENCES}

1. E. V. Zaretsky and W. J. Ander son, "Material Properties and Processing Variables and Their Effect on Rolling-Element Fatigue, " Paper presented at Dartmouth College Bearing Conference, Hanover, N.H. , Sept. 7-9, 1966.

2. E. V. Zaretsky, R. J. Parker, W. J. Anderson, and S. T. Miller, "Effect of Component Differential Hardness on Residual Stress and Rolling-Contact Fatigue, " NASA TN D-2664, 1965. 
3. J. O. Almen, "Effects of Residual Stress on Rolling Bodies," Rolling Contact Phenomena, J. B. Bidwell, editor, Elsevier Publishing Co., Inc., 1962, pp. 400-424.

4. J. J. Bush, W. L. Grube, and G. H. Robinson, "Microstructural and Residual Stress Changes in Hardened Steel Due to Rolling Contact, "Rolling Contact Phenomena, J. B. Bidwell, editor, Elsevier Publishing Co., Inc., 1962, pp. 365-399.

5. A. J. Gentile, E. F. Jordon, and A. D. Martin, "Phase Transformations in High-Carbon, High-Hardness Steels under Contract Loads," Transactions AIME, vol. 233, no. 6, June, 1965, pp. 1085-1093.

6. R. L. Scott, R. K. Kepple, and M. H. Miller, "The Effect of Processing-Induced Near-Surface Residual Stress on Ball Bearing Fatigue," Rolling Contact Phenomena, J. B. Bidwell, editor, Elsevier Publishing Co., Inc., 1962, pp. 301-316.

7. A. J. Gentile and A. D. Martin, "The Effects of Prior Metallurgically Induced Compressive Residual Stress on the Metallurgical and Endurance Properties of Overload-Tested Ball Bearings. ASME Paper No. 65-WA/CF-7, November, 1965.

8. D. W. Reichard, R. J. Parker, and E. V. Zaretsky, "Residual Stress and Subsurface Hardness Changes Induced During Rolling Contact," NASA TN D-4456, 1968.

9. E. V. Zaretsky, R. J. Parker, and W. J. Anderson, "Component Hardness Differences and Their Effect on Bearing Fatigue," Journal of Lubrication Technology, vol. 89, no. 1, January, 1967, pp. 47-62. 
10. E. V. Zaretsky, R. J. Parker, W. J. Anderson, and D. W. Reichard, "Bearing Life and Failure Distribution as Affected by Actual Component Differential Hardness, " NASA TN D-3101, 1965.

11. A. L. Christenson, D. P. Koistinen, R. E. Marburger, M. Semchysen, and W. P. Evans, "The Measurement of Stress by X-ray," SAE Information Series TR-182.

12. R. E. Marburger and D. P. Koistinen, "X-ray Measurement of Residual Stresses in Hardened Steel, " Internal Stress and Fatigue in Metals, G. M. Rassweiler and W. L. Grube, editors, Elsevier Publishing Co., Inc., 1959, pp. 98-109.

13. G. Lundberg and A. Palmgren, "Dynamic Capacity of Rolling Bearings," Acta Polytechnica, Mech. Eng. Ser., vol. 1, no. 3, 1947.

14. G. Lundberg and A. Palmgren, "Dynamic Capacity of Rolling Bearings, "Journal of Applied Mechanics, vol. 16, no. 2, June, 1949, pp. 165-172.

15. T. L. Carter, "A Study of Some Factors Affecting Rolling-Contact Fatigue Life," NASA TR R-60, 1960. 
Table 1. Ball tempering schedule for

SAE 52100 steel balls run in 207-size bearings [9]

[Ball diameter, 0.4375 in.; duration of each temper, $1 \mathrm{hr}$.]

\begin{tabular}{|c|c|c|}
\hline \multirow{2}{*}{$\begin{array}{c}\text { Nominal } \\
\text { Rockwell } \mathrm{C} \\
\text { hardness }\end{array}$} & \multicolumn{2}{|c|}{ Temperature, ${ }^{{ }^{\circ}} \mathrm{F}$} \\
\cline { 2 - 3 } & First temper & Second temper \\
\hline 60 & 250 & 435 \\
63 & 250 & 330 \\
65 & 250 & 260 \\
66 & 200 & None \\
\hline
\end{tabular}


Table 2. Nonmetallic inclusion ratings of SAE 52100 bearing material [9]

[Jernkontoret charts (ASTM Recommended Practice E45-51) ${ }^{\mathrm{a}}$.]

\begin{tabular}{|l|c|c|c|c|c|c|c|c|}
\hline $\begin{array}{l}\text { 207-Size } \\
\text { bearing } \\
\text { element }\end{array}$ & \multicolumn{4}{|c|}{ Thin series $^{\mathrm{A}}$} & \multicolumn{4}{c|}{ Thick series } \\
\cline { 2 - 9 } & A & B & C & D & A & B & C & D \\
\hline Balls & 1 & 1 to 2 & 1 to 2 & 3 to 5 & 1 & 1 to 2 & 1 to 2 & 1 to 3 \\
Races & 1 & 2 & 2 & 5 & 1 & 2 & 2 & 3 \\
\hline
\end{tabular}

$\mathrm{a}_{\text {Recommended Practice for Determining the Inclusion Content }}$ of Steel (E45-51), 1958 Book of ASTM Standards, Part 3, p. 529 .

besignation: $\mathrm{A}=$ sulfides, $\mathrm{B}=$ aluminates, $\mathrm{C}=$ silicates, $\mathrm{D}=$ oxides. 
Table 3. Measured residual stress with various values of component hardness difference, ${ }^{\mathrm{a}} \Delta \mathrm{H}$, for 207 -size deep-groove ball bearing inner races [Radial load, $1320 \mathrm{lb}$; inner-race speed, $2750 \mathrm{rpm}$.

\begin{tabular}{|c|c|c|c|c|c|c|c|c|c|c|}
\hline \multirow{3}{*}{$\begin{array}{c}\text { Component } \\
\text { hardness } \\
\text { difference, } \\
\Delta \mathrm{H}, \\
\text { Rockwell C }\end{array}$} & \multirow{3}{*}{$\begin{array}{l}\text { Running } \\
\text { time, } \\
\text { hr }\end{array}$} & \multicolumn{9}{|c|}{ Depth below running track surface, in. } \\
\hline & & 0 & 0.0005 & 0.001 & 0.002 & 0.003 & 0.004 & 0.005 & 0.006 & 0.007 \\
\hline & & \multicolumn{9}{|c|}{ Residual stress, $\mathrm{ksi}^{\mathrm{b}}$} \\
\hline \multicolumn{11}{|c|}{ Running times between 200 and $300 \mathrm{hr}$} \\
\hline-1.3 & 210 & -111 & -46 & -45 & -46 & -51 & -47 & -39 & -32 & -25 \\
\hline 1.1 & 210 & -92 & -37 & -27 & -30 & -28 & -24 & -18 & -13 & -11 \\
\hline 3.1 & 281 & -128 & -83 & -53 & -35 & -30 & -28 & -23 & -23 & -22 \\
\hline 3.6 & 230 & -95 & -48 & -33 & -26 & -21 & -18 & -15 & -16 & -13 \\
\hline \multicolumn{11}{|c|}{ Running times between 600 and $700 \mathrm{hr}$} \\
\hline-1.2 & 648 & -134 & +4 & +4 & +1 & -2 & -2 & -2 & -5 & -7 \\
\hline-1.2 & 697 & -142 & -69 & -40 & -14 & -9 & -6 & -8 & -8 & -7 \\
\hline-1.0 & 653 & -66 & -46 & -9 & -5 & -3 & -7 & -6 & -6 & -8 \\
\hline-.5 & 691 & -105 & -43 & -41 & -54 & -68 & -73 & -76 & -67 & -50 \\
\hline 1.3 & 665 & -98 & -81 & -94 & -103 & -97 & -88 & -79 & -69 & -58 \\
\hline 2.5 & 614 & -47 & -63 & -71 & -68 & -65 & -56 & -45 & -38 & -27 \\
\hline 2.7 & 700 & -92 & -99 & -66 & -53 & -53 & -49 & -43 & -38 & -28 \\
\hline 3.2 & 614 & -175 & -62 & -39 & -13 & -7 & -6 & -5 & -6 & -8 \\
\hline \multicolumn{11}{|c|}{ Running times between 1600 and $1800 \mathrm{hr}$} \\
\hline-1.1 & 1674 & -124 & +12 & +16 & +3 & +1 & -2 & -7 & -7 & -3 \\
\hline 1.2 & 1722 & -132 & -104 & -57 & -60 & -62 & -63 & -61 & -52 & -41 \\
\hline 1.6 & 1767 & -161 & -92 & -46 & -19 & -12 & -12 & -11 & -10 & -8 \\
\hline 2.2 & 1690 & -94 & -68 & -70 & -78 & -73 & -71 & -68 & -60 & -47 \\
\hline 2.7 & 1733 & -98 & -52 & -22 & -15 & -8 & -31 & -32 & -29 & -20 \\
\hline 3.5 & 1684 & -94 & -90 & -44 & -10 & -11 & -11 & -11 & -7 & -4 \\
\hline 3.5 & 1764 & -88 & -100 & -50 & -18 & -19 & -15 & -18 & -15 & -10 \\
\hline
\end{tabular}

${ }^{\mathrm{a}}$ Ball hardness minus race hardness, Rockwell $\mathrm{C}$ scale.

${ }^{b}$ Positive values denote tensile stress, negative values denote compressive stress. 
Table 4. Relative predicted fatigue lives based on residual stress measurements of 207-size deep-groove ball-bearing inner races for various values of component hardness difference $\Delta \mathrm{H}$

\begin{tabular}{|c|c|c|c|}
\hline $\begin{array}{c}\text { Component hardness } \\
\text { difference }{ }^{\mathrm{a}} \\
\text { range, } \\
\Delta \mathrm{H}, \\
\text { Rockwell C }\end{array}$ & $\begin{array}{l}\text { Average } \\
\text { compressive } \\
\text { residual } \\
\text { stress } \\
\text { value, } \\
\text { ksi }\end{array}$ & $\begin{array}{c}\text { Relative } \\
\text { predicted } \\
\text { 10-percent } \\
\text { life from } \\
\text { residual } \\
\text { stress }\end{array}$ & $\begin{array}{c}\text { Relative } \\
\text { experimental } \\
\text { 10-percent } \\
\text { life } \mathrm{e}^{\mathrm{b}} \\
{\left[\begin{array}{ll}9 & \text { and } 10\end{array}\right]}\end{array}$ \\
\hline-2.0 to -1.0 & 6 & 0.06 & 0.07 \\
\hline-1.0 to 0 & 36 & .19 & .23 \\
\hline 0 to 1.0 & -- & --- & $-\ldots$ \\
\hline 1.0 to 2.0 & 69 & 1.00 & 1.00 \\
\hline 2.0 to 3.0 & 38 & .23 & .83 \\
\hline 3.0 to 4.0 & 6 & .06 & .60 \\
\hline
\end{tabular}

${ }^{a}$ Ball hardness minus race hardness, Rockwell C scale.

${ }^{b}$ Relative to value at $\Delta \mathrm{H}$ range 1.0 to 2.0 . 


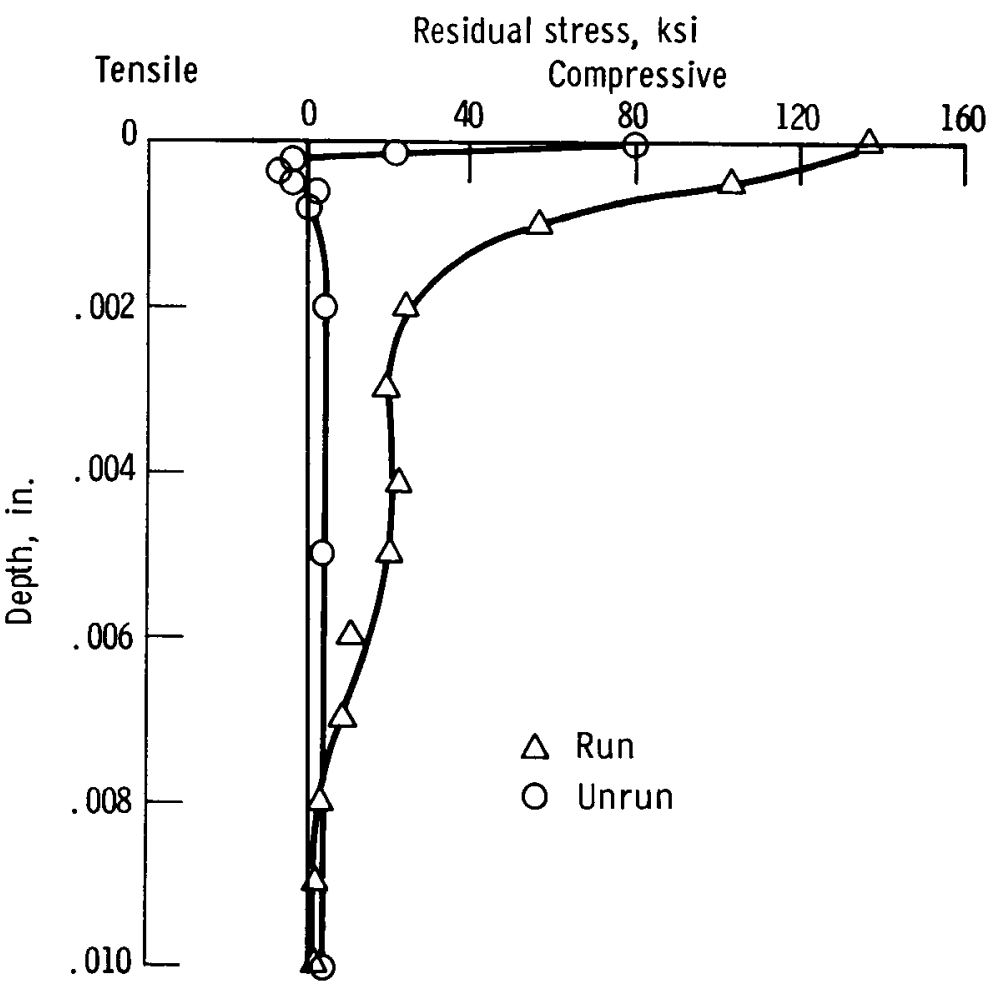

Figure 1. - Residual stress as function of depth below surface of 207-size deepgroove bearing inner races in both run (duration, $3480 \mathrm{hr}$ ) and unrun condition. Component hardness difference, $\Delta H=2.0$ [9]. 


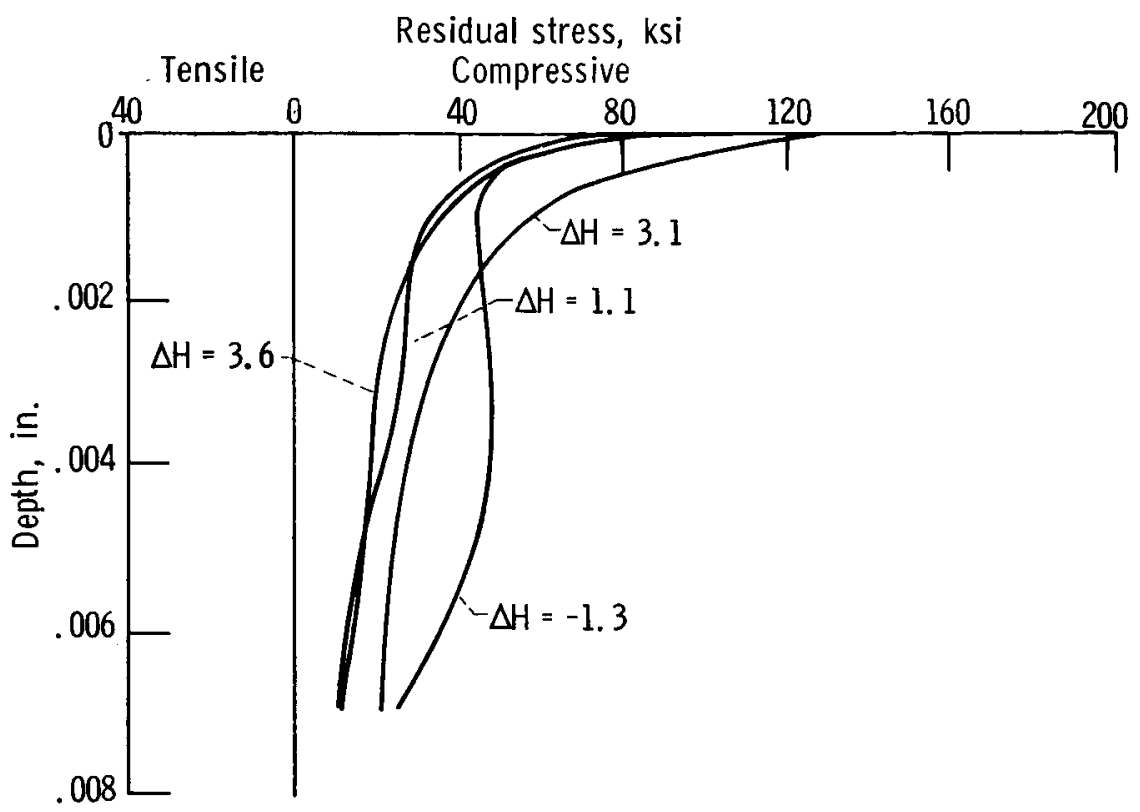

(a) Running times between 200 and 300 hours.

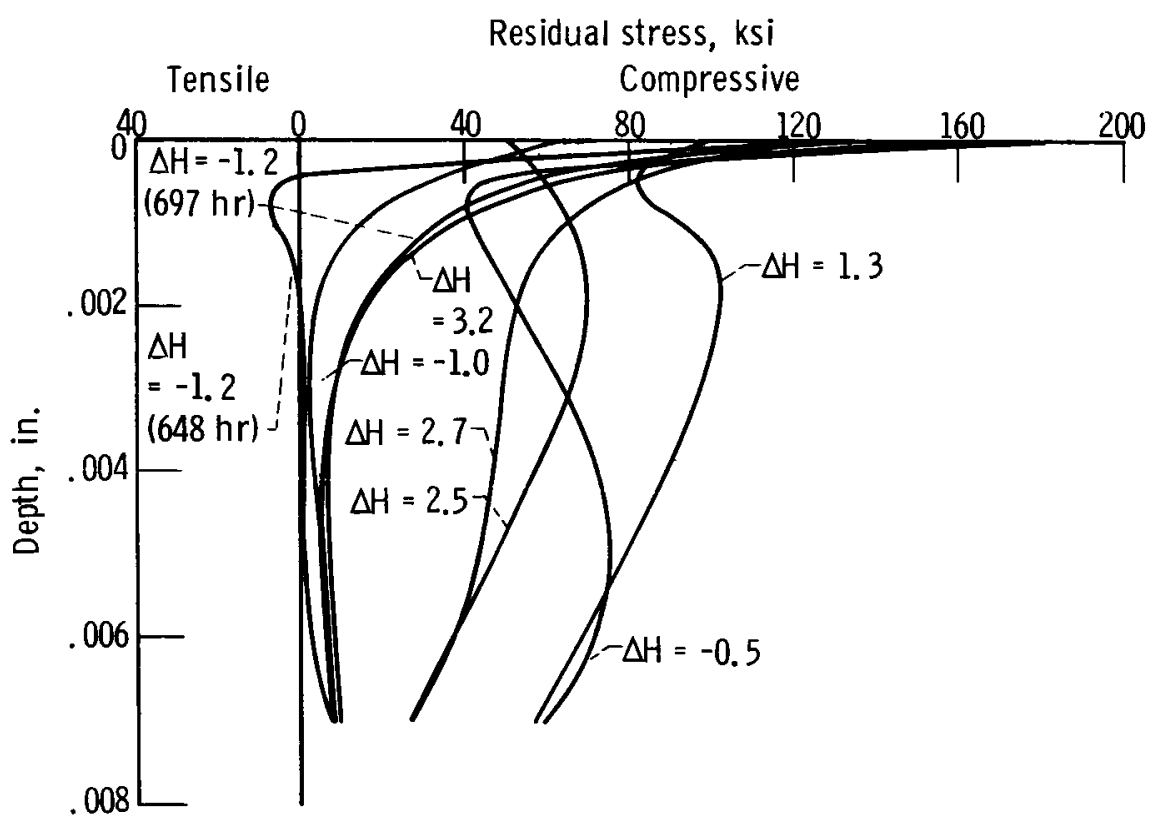

(b) Running times between 600 and 700 hours.

Figure 2. - Residual stress as function of depth for 207-size deepgroove ball bearings with various values of component hardness difference $\Delta \mathrm{H}$ (ball hardness minus race hardness). Ball and race material, SAE 52100 steel; radial load, 1320 pounds; innerrace speed, $2750 \mathrm{rpm}$; no heat added. 


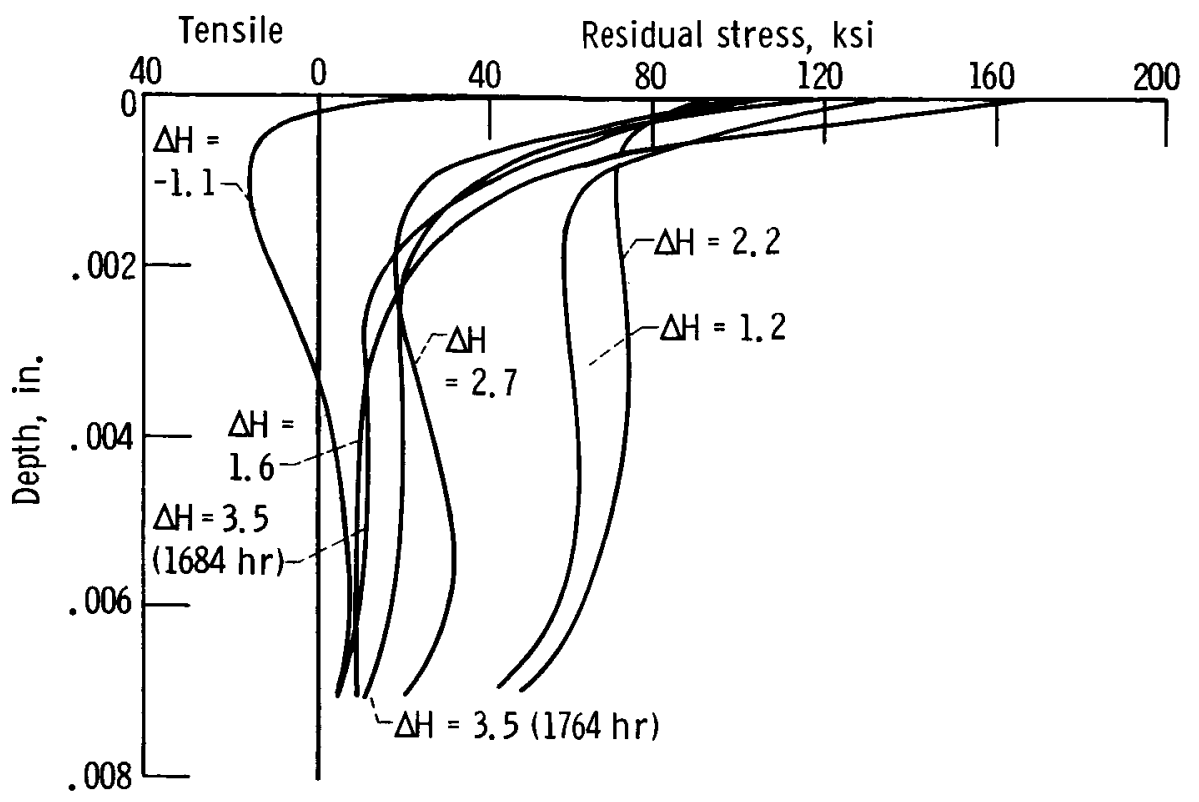

(c) Running times between 1600 and 1800 hours.

Figure 2. - Concluded.
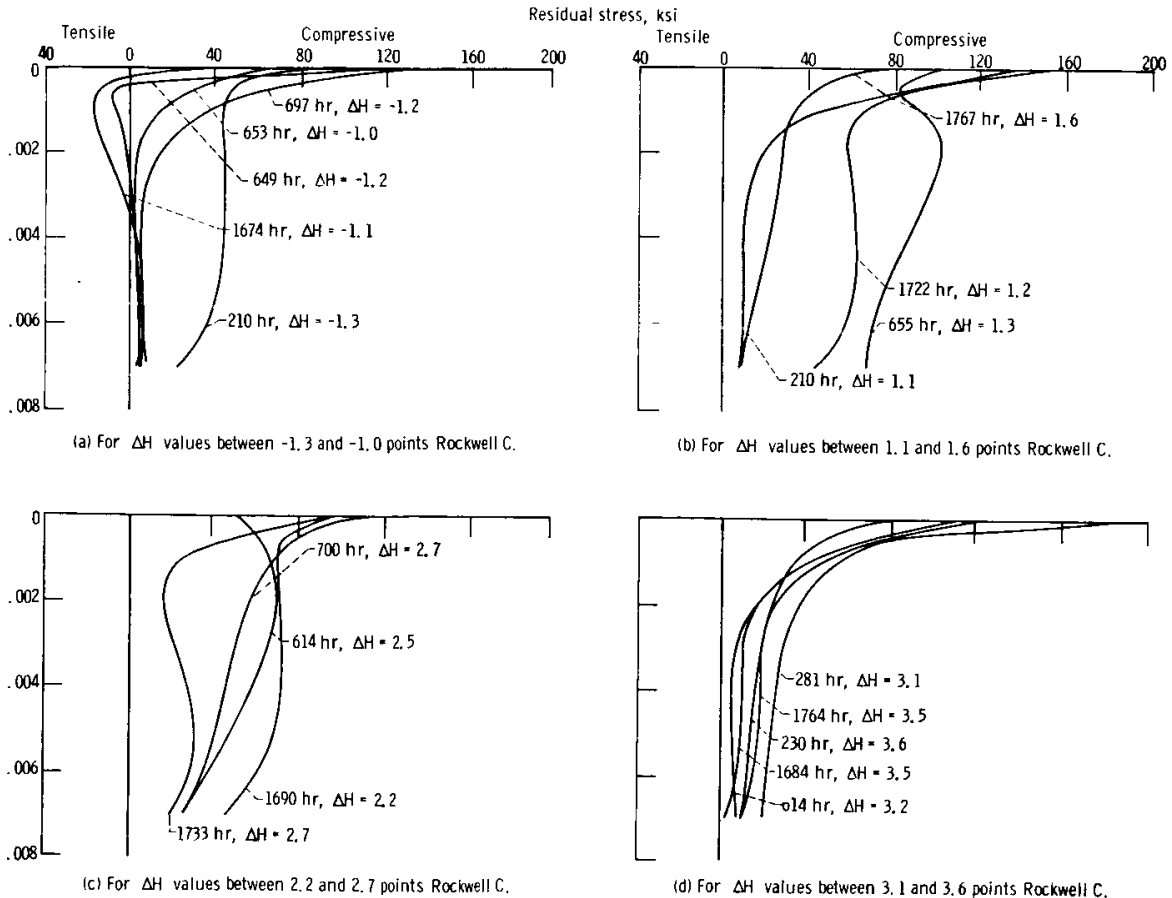

Figure 3. - Residual stress as function of depth with various running times for 207 -size deep-groove bearing inner races. 